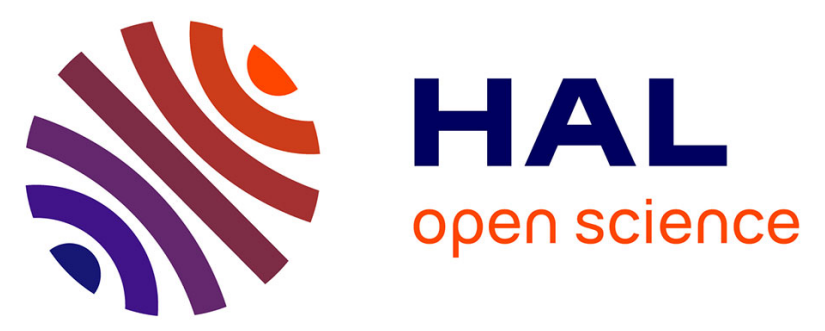

\title{
Peripherally multi-functionalised metallosupramolecular grids: assembly, decoration, building blocks for dynamic covalent architectures
}

Jan Holub, Antonio Santoro, Mihail-Adrian Stadler, Jean-Marie Lehn

\section{- To cite this version:}

Jan Holub, Antonio Santoro, Mihail-Adrian Stadler, Jean-Marie Lehn. Peripherally multifunctionalised metallosupramolecular grids: assembly, decoration, building blocks for dynamic covalent architectures. Inorganic Chemistry Frontiers, 2021, 10.1039/D1QI01084K . hal-03442118

\author{
HAL Id: hal-03442118 \\ https://hal.science/hal-03442118
}

Submitted on 23 Nov 2021

HAL is a multi-disciplinary open access archive for the deposit and dissemination of scientific research documents, whether they are published or not. The documents may come from teaching and research institutions in France or abroad, or from public or private research centers.
L'archive ouverte pluridisciplinaire HAL, est destinée au dépôt et à la diffusion de documents scientifiques de niveau recherche, publiés ou non, émanant des établissements d'enseignement et de recherche français ou étrangers, des laboratoires publics ou privés. 


\title{
Peripherally Multi-Functionalised Metallosupramolecular Grids: Assembly, Decoration, Building Blocks for Dynamic Covalent Architectures
}

\author{
Jan Holub $^{\mathrm{a}, \mathrm{b}}$, Antonio Santoro ${ }^{\mathrm{a}, \mathrm{c}}$, Mihail-Adrian Stadler $^{\mathrm{a}}$, Jean-Marie Lehn ${ }^{\mathrm{a}^{*}}$
}

\begin{abstract}
${ }^{a}$ Laboratoire de Chimie Supramoléculaire, ISIS, Université de Strasbourg, 8 Allée Gaspard Monge, 67000 Strasbourg, France

${ }^{\mathrm{b}}$ Present address: Department of Chemistry, University of Cambridge, Lensfield Road, Cambridge CB2 1EW, U.K.

${ }^{c}$ Present address: Department of Chemical, Biological, Pharmaceutical and Environmental Sciences, University of Messina, Viale F. Stagno d'Alcontres 31, 98166 Messina, Italy
\end{abstract}

\begin{abstract}
:
The sequential assembly of first terminally functionalized bishydrazone ligands followed by their coordination with Zn(II) metal cations yields peripherallymulti-functionalized [2x2] grid-type complexes. In particular, the introduction of aldehyde functional groups results in the generation of octavalent grids bearing eightreactive aldehyde units positioned in-plane on its outer rim. Their successful condensationwith various amines and hydrazines introduces reversibly connected imine/hydrazone sidechains. It pointsto their potential as a metallosupramolecular platform for executing diverse "second-shell" dynamic covalent decorations and for their implementation as building block for dynamic architectures. Thus, connection of two of the bishydrazone ligands in the grid complex with a difunctional covalent linker led to the formation of folded molecular grids of "double hairpins" geometry. These double hairpins grid architectures present two faces accessible for functionalization and twoorthogonal ones that are blocked by the bent linker. This directionality was exploited in the second generation of folded grids/double hairpins, which were purposely decorated with aldehyde groups in order to perform multi-functional dynamic covalent chemistry and give access to novel complex architectures such as "grid of grids" arrays. The promising conjunction of a spatial organization of grids together with the endless diversity of imine dynamic chemistryprovides an appealing basis for further development along various fieldsof interest (e.g.: multivalency, dynamic assembly of grids arrays, multifunctional decoration, etc.).
\end{abstract}

The designed generation of metallosupramolecular (MetSup) architectures is being actively pursued for a great variety of purposes [1]. Many types are known, many preparation methods described, and many applications suggested. However, to generate the highly complex functional assemblies, the precise connectivity of their building blocks must be ensured by 
decoration with specifically positioned functional appendages.In this regard, decoratedordered complexes of grid-type structurehavealready drawn much attention [2].

In materials chemistry, multicomponent grid-like arrays are potential constituents of nanoscale electronic devices [1-4]serving for instance as points capable of current transmission and beyond, inso called "quantum cellular automata", where information storage is based on an array of different redox states organized in specific patterns[2a, 3].

There are several means forbestowing to MetSupgrids different attributes for different purposes. Besidesthe obvious choice of the metal cation inducing the assembly, the substitution on the ligand backbone may also serve for subtle tuning of the physicochemical features and performance of the complex. Among other effects, electron-donating or accepting groups influence the energy transfer between the metal centre and the ligand or the spin-spin transition energies. [4f] Grids with different backbone modifications were already successfully used in surface templated assembly of 2D arrays [5], crystal engineering [2a][6], multivalence capacity [7a,b], external substrate binding [7c] and external stimuli responsive systems [2e][8][9].

Such a wide range of applications is made possible by the availability of several functional levels. At first, the dynamic assembly provides geometrically and structurally well-defined complexes. Already at this level, the right choice of cations and ligands bestows on the grids useful functional attributes (conductivity, magnetism, fluorescence) [2][4][10]. Moreover, the multicomponent nature of even the most basic [2x2] grids, incorporating four ligands and bearing substituents on their periphery, provides complexes that display eight (and in principle up to sixteen when combining axial and lateral substituents) functionalities. This directly reveals the predisposition of grid-type architectures towards multivalency. [2][7]

Furthermore, peripheral functionalization by sidechains bearing suitable functional groups (such as carbonyl or amino) confers to the grid units the opportunity to serve as platforms for Dynamic Covalent Chemistry (DCC) [11] and participate in dynamic exchange reactions giving access to dynamic decoration [7b, 12]. The implementation of the dynamic covalent approach thus provides a simple and powerful means for insertion of various additional functionalities on the grid, their subsequent exchange/alternation and modulation.

Building on our previous experiencewith bishydrazone based ligands and their grid-type complexes, the present work focuses on the introduction of aldehyde functionalities onto the periphery of [2x2] grids and theirsubsequent decoration via imine formation by (reversible) reaction with compounds bearing primary amino groups. 


\section{Multiple functionalized grid architectures for multivalency and bottom-up array assembly}

The implementation of functional building blocks, such as metallosupramolecular gridtype entities, in functional nanoscale devices requires their precise surface positioning forfacile accessibility/modulabilityas well as exact localisation for repeated access/reading. It is thus imperative to provide ways and means (non-covalent or covalent) to assemble the basic units into ordered arrays of specific dimensionality or other well-defined architectures. [5][6]. For example, two-step organization through hydrogen bonding and metal cation coordination has been already described in the crystalline solid state of suitably functionalized grid-type complexes. [6a, b, c] Atemplated array assembledon a flat surface [2a][5]allowed to significantly reduce the mobility of individual molecules in comparison to simple array of alkanes [2a, 5a, b]. To further enhance the reduction in the mobility,it is desirable tostrengthen intermolecular interactions within the array. In this context,DCC offers appealing features of reversible bond formationsimultaneously providing covalent interconnection (e.g.: imine bonds) while allowing for "self-healing/repairing" of the defects within supramolecular framework of higher complexity.

The goal of the present work was to design and prepare a hydrazone based ligands decorated withaldehyde groups at their periphery, capable to participate in imine formation/exchange processes [13]Here, wepresent such tailor-made ligands with terminal aldehyde groups, their grid assembly in a presence of $\mathrm{Zn}(\mathrm{II})$ cation and imine decoration of their periphery.

The herein described ligands incorporating two hydrazone units may exist in two constitutional isomers L1 and L2 (Figure 1), which differ in the orientation of their hydrazone

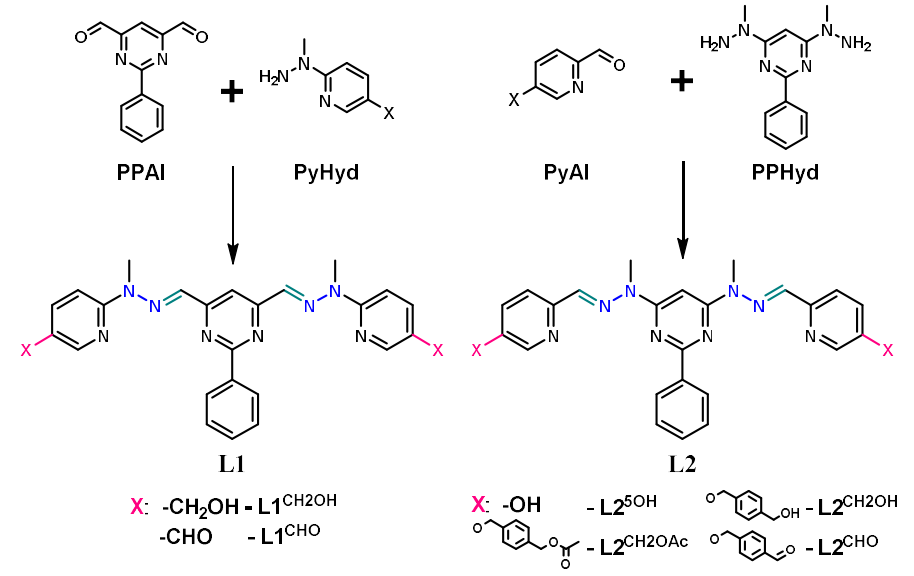

Figure 1: Illustrative representation of the symmetrically functionalized grid ligands of $\mathbf{L} \mathbf{1}$ and L2 family. bond. Consequently, the chemical and physical properties of both isomers differ $[14,15]$ as well as their respective synthetic paths. In this work, both isomers were used in different stages according to the synthetic feasibility of the required peripheral functionalization. The general synthetic paths as well as the 
general features of both isomers are already well described elsewhere in the literature. [14, 15]Herein, we describe only the specifics connected with the introduction and behaviour of peripheral aldehyde groups.

We first investigated ligands $\mathbf{L 1}^{\mathbf{C H 2 O H}}$ and $\mathbf{L 1}{ }^{\mathbf{C H O}}$ of $\mathbf{L 1}$ type (Figure 1, Left) based on the condensation of a central pyrimidine dialdehyde with two suitably functionalized hydrazine lateral residues.Here, the synthetic challenge towards $\mathbf{L 1}^{\mathbf{C H O}}$ lies in the selective orthogonal introduction of an aldehyde group next to a relatively fragile $-C=N$ - bond(Figures 1 and 2). We found that the well-established Dess-Martin (DM)reagent may serve asa mild and selective oxidant of primary alcohols to aldehydes without any effect on the hydrazone backbone. Therefore, the synthetic sequence started with a pre-formation of hydroxymethyl bishydrazone ligand $\mathbf{L 1}^{\mathbf{C H}^{2} \mathrm{OH}_{\text {and }}}$ was followed by DM oxidation of hydroxymethyl groups in $\mathrm{CH}_{2} \mathrm{Cl}_{2}$ at room temperature. The desired ligand $\mathbf{L 1}{ }^{\mathbf{C H O}}$ directly precipitated from the reaction mixture as yellow solidin 75\%yield (ESI Figures S1-S4). The detailed synthetic procedures can be found in ESI. It was found that unfortunately neither hydroxymethyl ligand $\mathbf{L 1}^{\mathbf{C H} 2 \mathrm{OH}}$ nor dialdehyde ligand $\mathbf{L 1}^{\mathbf{C H O}}$ assemble in the presence of Zinc Triflate $\left(\mathrm{Zn}(\mathrm{OTf})_{2}\right)$ into a grid complex.

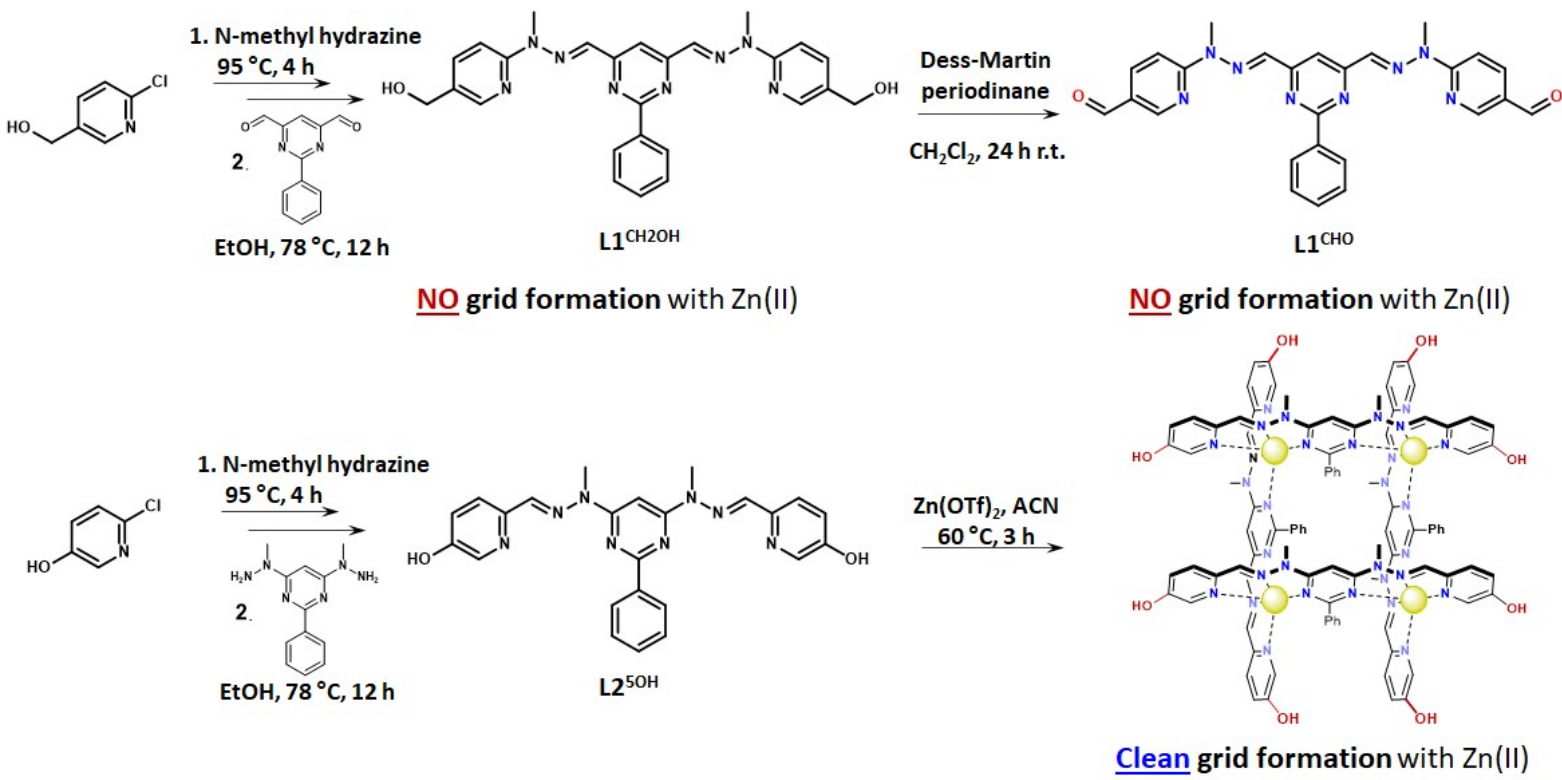

Figure 2: Top: Synthetic path to the dialdehyde ligand L1 $^{\text {CHO }}$. Bottom: Synthesis of $\mathbf{L 2}^{\mathbf{5 O H}}$ and its clean $\mathrm{Zn}_{4}[2 \times 2]$ grid assembly [14]

We then turned to ligands of the opposite constitutional isomer type $\mathbf{L} 2$ resulting from the condensation of a central pyrimidine bis-hydrazine with two lateral aldehyde residues. The orientation of the hydrazone unit represents a major difference between the $\mathbf{L 1}$ and $\mathbf{L 2}$ structural types. The $-\mathrm{N}(\mathrm{Me})$ - sites conjugated to the pyrimidine group in the $\mathbf{L} 2$ type may 
be expected to make the pyrimidine nitrogensbetter binding sites than in L1. Indeed,we previously reported the successful assembly of $\mathbf{L 2}^{\mathbf{5 O H}}$ into a grid complex with $\mathrm{Zn}$ (II) [14] (Figure 2, Bottom). Furthermore, the failure of a grid formation in $\mathbf{L 1}^{\mathrm{CH} 2 \mathrm{OH}}$ and $\mathrm{L1}^{\mathrm{CHO}}$ may also involve some hindrance between the ligands themselves or with $\mathrm{Zn}$ (II) cations in the core of the complex. Presuming that a larger distance between the ligand coreand the aldehyde might alleviate these interactions, a new extended ligand design ( $\mathbf{L 2}^{\mathbf{C H O}}$, Figure 3$)$ containing an additional phenyl spacerwas chosen.

Three ligands of this type were synthesized following the pathway shown in Figure 1, Right by the stepwise procedure (Figure 3 Top). These ligands led to a clean assembly into grid-type complexes with Zn(II) (Figure 3). A one pot procedure was also investigated for the synthesis of $\mathbf{L 2}^{\mathbf{C H O}}$ by mixing the substituted pyridine aldehyde $\mathrm{PhPyAl}_{2}$ with the bishydrazino-pyrimidine in presence of $\mathrm{Zn}(\mathrm{II})$ (Figure 3 Bottom). The one-pot procedure $\mathbf{L 2}^{\mathrm{CHO}}$ is described in the ESI (ESI Figure S8). A formation of the [2x2] grid structure could be deduced from the appearance of the characteristic peaks (two doublets in 5-6 ppm [10][15d]) in the ${ }^{1} \mathrm{H}$-NMR spectrum of the reaction mixture. The corresponding $\mathbf{L 2}{ }^{\mathbf{C H O}}{ }_{4} \mathbf{Z n}_{4}$ grid complex was obtained in high yield but was not clean. Therefore, the stepwise procedure was preferentially used.

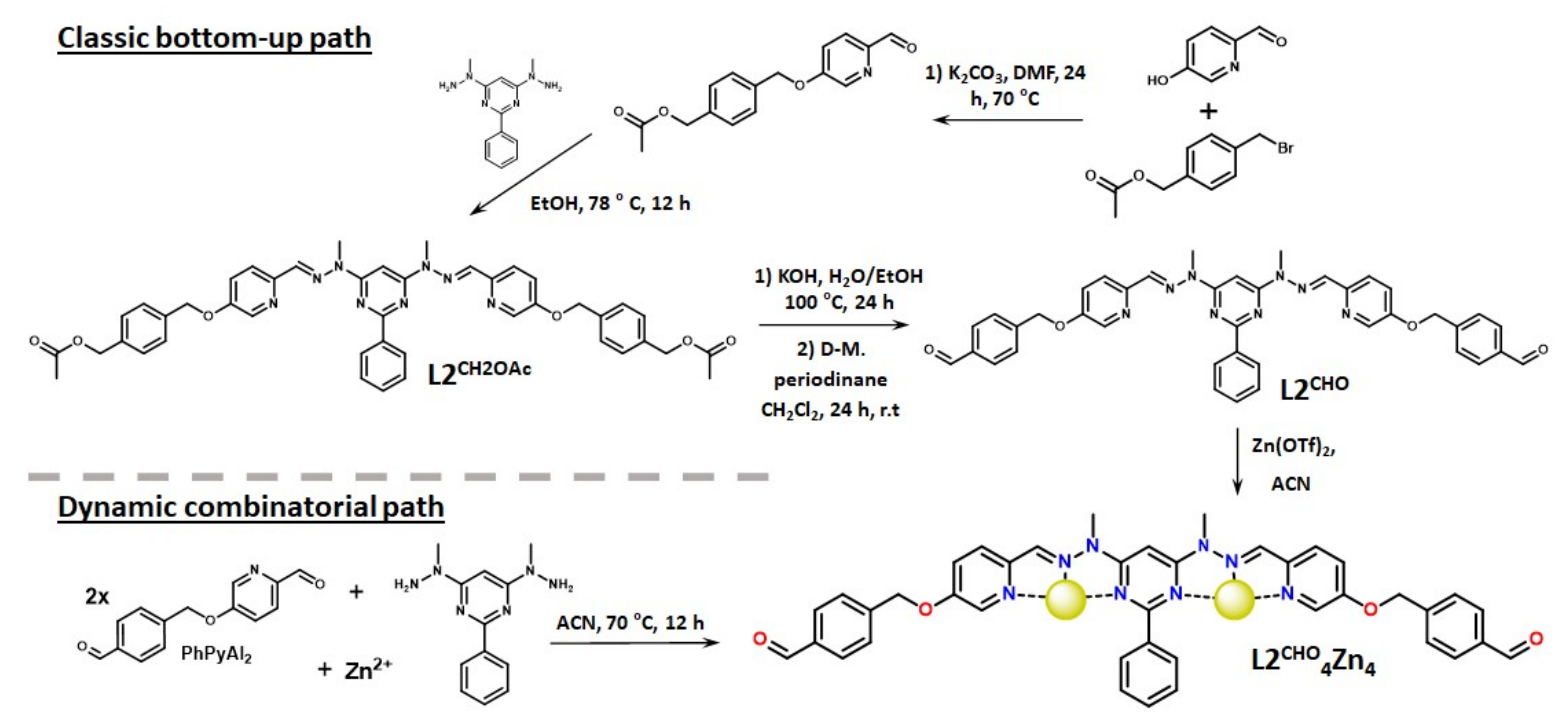

Figure 3: Top: Illustration of the stepwise synthetic path to the ligand $\mathbf{L} 2^{\mathrm{CHO}}$ and the complex $\mathbf{L 2}^{\mathrm{CHO}}{ }_{4} \mathbf{Z n}_{4}$. Inset: Crystal structure of $\mathbf{L}{ }^{\mathrm{CHO}}{ }_{4} \mathbf{Z n}_{4}$ Bottom: Dynamic approach to formation of multialdehyde grid complex $\mathbf{L 2}^{\mathrm{CHO}}{ }_{4} \mathbf{Z n}_{4}$.

The bottom-up retrosynthetic path was centredon the introduction of a benzyl alcohol fragment at the extremities of the extended ligand $\mathbf{L 2}^{\mathbf{C H 2 O H}}$. (Figure 3Top) Due to the very good resistance of the hydrazone cores towards harsh basic conditions $\left(\mathrm{KOH} / \mathrm{H}_{2} \mathrm{O} / \mathrm{EtOH}\right)$, the acetyl ester ( $\left.\mathbf{L} \mathbf{2}^{\mathbf{O A c M e}}\right)$ was seen as an ideal protecting group. The actual synthesis is then very 
straightforward and is depicted in the Figure 3, Top(See ESI for details).After base deprotection, the final $\mathbf{L} 2^{\mathbf{C H O}}$ ligand is obtained through DM+ oxidation and directly collected from $\mathrm{CH}_{2} \mathrm{Cl}_{2}$ as an off-white precipitate (ESI Figure S21).

The complete pre-formed $\mathbf{L 2}^{\mathbf{C H O}}$ ligand assembled cleanly in the presence of $\mathrm{Zn}$ (II) into the $\mathbf{L 2}^{\mathbf{C H O}}{ }_{4} \mathbf{Z n}_{4}$ grid(ESI Figure S8 and S23-S28). Itsstructure was further confirmed with Xray analysis (Figure 5, R1 $=5.00 \%$, ESI) unequivocally proving the expected [2x2] grid structure with eight pendant aldehyde groups protruding from the horizontal plane of the complex.

In addition to grid formation, several studies recently reported an interconversion of bishydrazone ligands into double helicates using a tetrahedrally coordinating metals[2e][9].If the same was possible with $\mathbf{L} 2^{\mathbf{C H O}}$ the formation of an aldehyde decorated double helicate would be complementary to the formation of a [2×2] grid.

Adding an acetonitrile solution of $\operatorname{AgOTf}\left(1\right.$ eq.) to the ligand $\mathbf{L 2}^{\mathbf{C H O}}(1$ eq.) provided the double helicateL2 ${ }^{\mathbf{C H O}}{ }_{2} \mathbf{A g}_{2}$ (ESI Figures S30-S33), which structurewas confirmed by X-ray crystallography $(\mathrm{R} 1=7.23 \%$, Figure 4$)$. Interestingly, the helicate crystalizes in a form of a dimer involving a short Ag-Ag contact of $3.07 \AA$. However, the $\mathrm{C}_{2 \mathrm{v}}$ symmetric nature of its ${ }^{1} \mathrm{H}$ NMR spectrum (see ESI Figures S30 and S33) indicates that no such pairing occurs in solution.

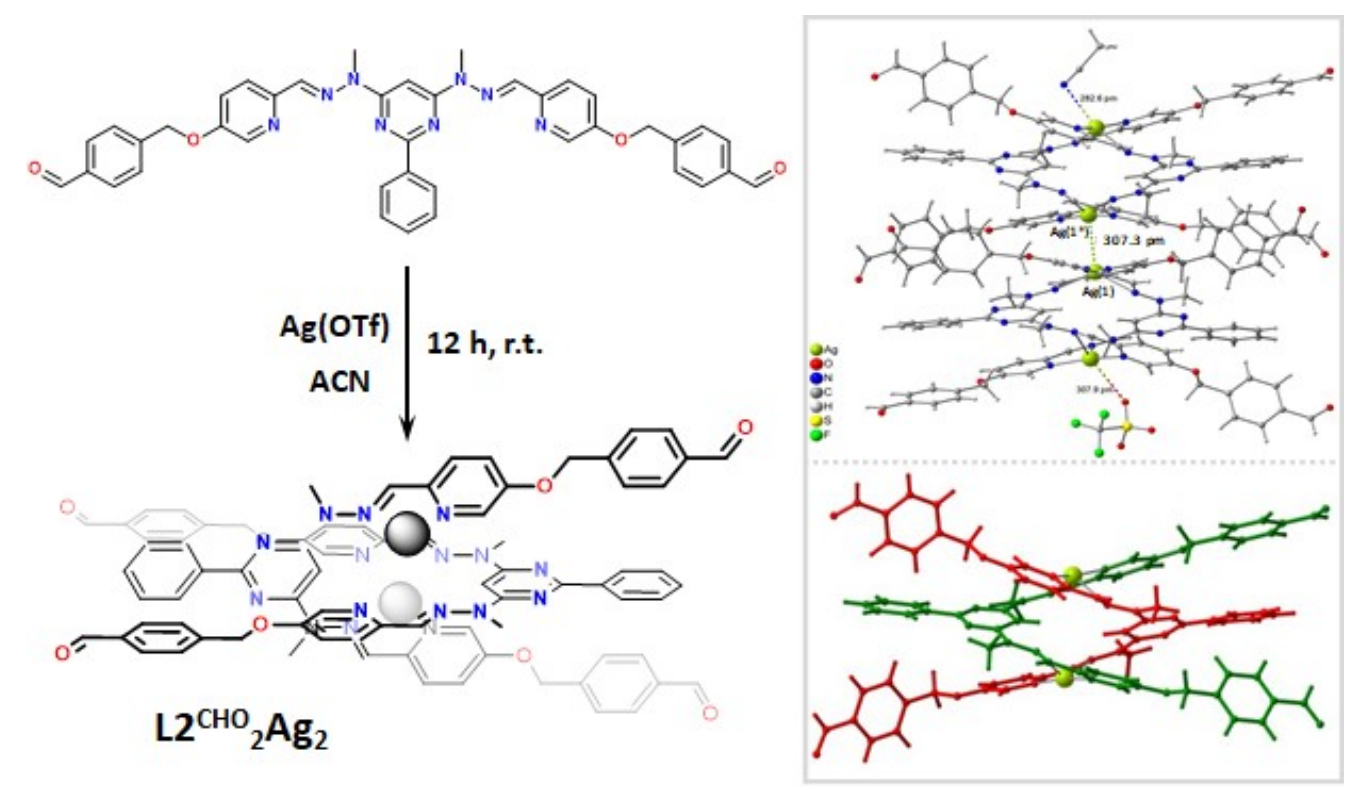

Figure 4: Left: The illustration of the ligand configuration in the $\left[\mathbf{L 2}^{\mathrm{CHO}}{ }_{2} \mathrm{Ag}_{2}\right](\mathrm{OTf})_{2}$. Right: representation of the double helicate $\mathbf{L}^{\mathrm{CHO}}{ }_{2} \mathrm{Ag}_{2}$ and its dimeric nature in a solid state.

The formation of an aldehyde decorated double helicate brings an additional level of complexity to the present MetSupassemblies as well as a control over the number of 
functional units in multivalency studies as the double helicate bears only four aldehyde groups.

With aldehyde decorated ligands and grids in hand, we testedtheir dynamic decoration with three different amino compounds. (Figure 5Top) In the case of 1-(methyl)-1-phenylhydrazine the ${ }^{1} \mathrm{H}$ NMR and ESI-MS data indicate that the condensation achieves total conversion of peripheral aldehydes into hydrazones (ESI Figure S39-41). Slow vapour diffusion of diethyl ether into thereaction mixture inacetonitrile provided single crystals for X-ray analysis. Unfortunately, the structure could be solved only with low refinement due to the large conformational disorder of the side branches and solvent $\left(\mathrm{R} 1=23.30 \%, \mathbf{L 2}^{\mathrm{CHN}}{ }_{4} \mathbf{Z n}_{4}(\mathbf{N}-\right.$ MePhHydr), see ESI Figure S42). Nevertheless, it is still possible to undoubtedlyrecognize the newly formed hydrazone bond on the periphery of the ligand+as well as the integrity of the central grid moiety.

Amines such as $n$-butylamine and $p$-toluidinewere alsosuccessfully grafted onto the periphery of the grid (Figure 5Top). However, in these cases a small amount of unreacted aldehyde and amine can still be identified in the ${ }^{1} \mathrm{H}$ NMR spectra. (See ESI Figure S35-S38) 


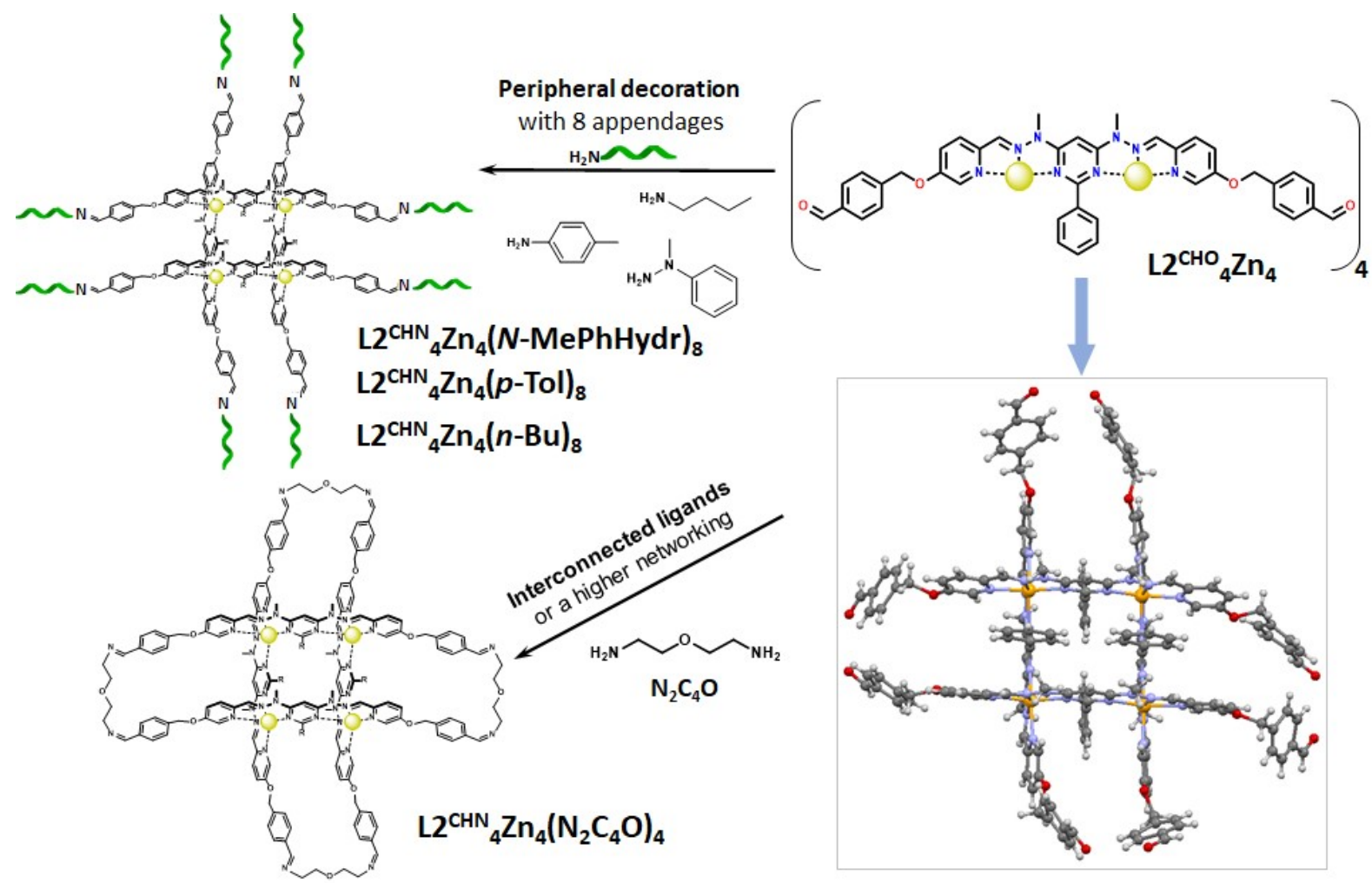

Figure 5: Top: The depiction of the DCC decorationof $\mathbf{L 2}^{\mathbf{C H O}}{ }_{4} \mathrm{Zn}_{4}$ and with amines and hydrazone;Bottom Left: Imine bridged $\mathrm{L2}^{\mathrm{CHN}}{ }_{4} \mathrm{Zn}_{4}\left(\mathrm{~N}_{2} \mathrm{C}_{4} \mathrm{O}\right)_{4}$ obtained from the reaction of 2(2-Aminoethoxy)ethylamine $\left(\mathbf{N}_{2} C_{4} \mathbf{O}\right)$ with $\mathbf{L 2}^{\mathrm{CHN}}{ }_{4} \mathbf{Z n}_{4}$; ; Bottom Right:The single crystal X-ray structure of $\mathbf{L} 2^{\mathrm{CHO}}{ }_{4} \mathrm{Zn}_{4}$.

Finally, the possibility of bottom-up formation of $2 \mathrm{D}$ array from $\mathbf{L 2}^{\mathrm{CHO}}{ }_{4} \mathbf{Z n}_{4}$ was tested by reaction with aliphatic diamines.The addition of 1 eq. of diamine could interconnect the individual gridunits and lead to the formation ofa large network. Thus, 2-(2aminoethoxy)ethylamine $\left(\mathbf{N}_{2} \mathbf{C}_{4} \mathbf{O}\right)$ was mixed with $\mathbf{L 2}^{\mathbf{C H O}}{ }_{4} \mathbf{Z n}_{4}$ in acetonitrile. Overnight standing at r.t. led to a white precipitate insoluble in all common organic solvents, whose compositioncould not be elucidated so far.Conversely, the ${ }^{1} \mathrm{H}$ NMR spectrum of the remaining supernatantshowed the presence ofa well-defined grid structure. (Figure 5 Bottom Left, See ESI Figure S43). HR-ESI mass spectrometrypoints to the formation of a symmetric four times interconnected grid structure $\left(\mathbf{L 2}^{\mathbf{C H N}}{ }_{4} \mathbf{Z n}_{4}\left(\mathbf{N}_{2} \mathbf{C}_{4} \mathbf{O}\right)_{4}\right.$, Figure 5 Bottom, ESIFigure S45). Unfortunately, to this day it was not possible to obtain crystallographic evidence of this structure.

\section{Double-subunit ligands for double hairpinassembly - Special case of [2x2] grids}

Synthesis of double-subunit ligands. 


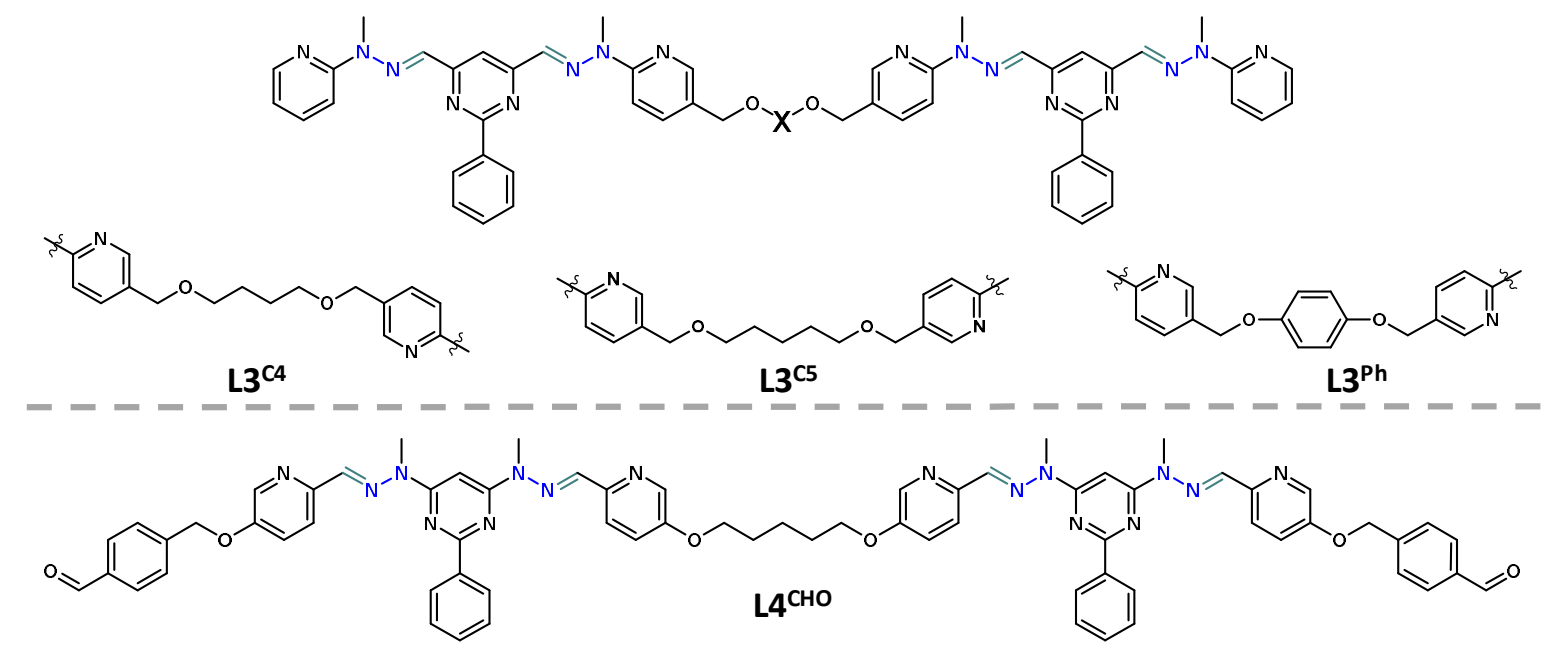

Figure 6:Top: Structures of the ligands of the double-subunit L3 ${ }^{X}$ family. Bottom: Structure of the improved ligand $\mathbf{L} 4^{X}$ with terminal aldehyde functionalization.

The designed assembly of polytopic ligands containing multiple subunits is still a challenging process.[2c, d][16] Implementing the experience gained in previous work and combining rational design with dynamic covalent chemistry, we studied the assembly and the features of a series of double-subunit grid ligands represented in Figure 6.

Their backboneconsists of two above described bishydrazone ligands connected through an organic linker $\left(\mathbf{L 3}^{\mathbf{X}}\right)$ andaddition ofterminal aldehyde groups $\left(\mathbf{L 4}^{\mathbf{X}}\right)$ (Figure 6). The straightforward synthetic pathway (Figure 7) allowed for the preparationof the initial $\mathbf{L 3}{ }^{\mathbf{X}}$ ligands family bridged with aliphatic and aromatic linkers (Figure 6 Top). The convergent synthesis started withmonosubstituted aldehyde PyHyd-PPAl, whichwasobtained by the condensation of 1 eq. PyHydand 1 eq. PPAl in ethanol with 30\% isolated yield. Thebridging unit ( $\mathbf{L 3}^{\mathbf{X}} \mathbf{C l}_{2}$ ) wasformed by reaction of (5-chloromethyl)-2-chloropyridine with an appropriate diol in dry DMF in a presence of $\mathrm{NaH}$ in $40-60 \%$ yield depending on the substrate (see ESI Figures S46-S51). Subsequent heating of the $\mathbf{L 3}^{\mathbf{X}} \mathbf{C l}_{\mathbf{2}}$ compounds in methylhydrazine affordedthe corresponding dihydrazine derivatives $\left(\mathbf{L 3}^{\mathbf{X}} \mathbf{H y d}_{2}\right)$ in $80-90 \%$ yield (See ESI Figures S52-S57). Finally, the condensation of the monoaldehydePyHyd-PPAl with adihydrazine bridgeprovidedthe final double subunit structures $\left(\mathbf{L 3}^{\mathbf{X}}\right)$ in high yields (about $<90 \%$; Figure 7, for detailed procedures see ESI and Figures S60-S67). 


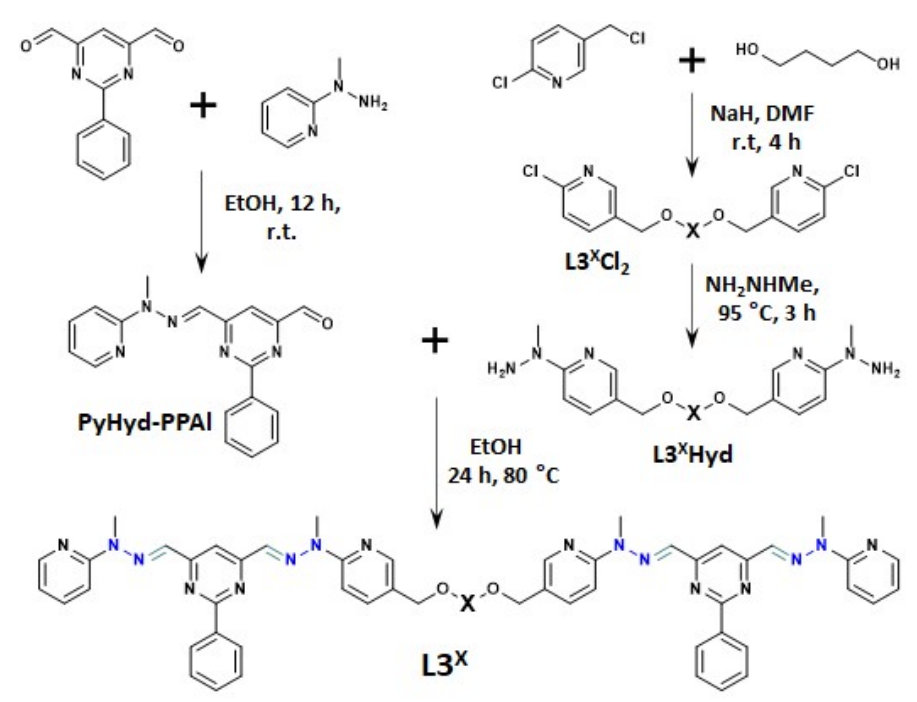

In extension to $\mathbf{L 3}^{\mathbf{X}}$, double subunit ligands bearing terminal aldehyde groups (L4 ${ }^{\mathbf{X}}$, Figure 6 Bottom) were designed and successfully prepared.The synthetic path (Figure 8, for synthetic details see ESI) closely follows that already described for $\mathbf{L 2}{ }^{\mathbf{C H O}}$ with the key step being the condensation of the monohydrazine $\mathrm{H}_{2} \mathrm{NL}_{4}^{\text {CH2OAc}}$ (see ESI

Figure 7:Illustrative synthetic path towards the Figure S68) with bridging aliphatic family of hydrazone based $\mathbf{L 3}^{\boldsymbol{X}}$ double subunits dialdehydes $\mathbf{P y}_{\mathbf{2}} \mathbf{C}_{\mathbf{5}} \mathbf{A l}_{\mathbf{2}}$ (pentyl bridge, ligands.

L4 ${ }^{\text {CH2OAc }}$, ESI Figures S70-74). This step was followed by the already described sequence of basic hydroxyl deprotection $\left(\mathbf{L 4}^{\mathbf{C H 2 O H}}\right)$ and Dess-Marten oxidation. This sequence furnished the desired ligand $\mathbf{L 4}^{\mathbf{C H O}}$ with two terminal aldehyde-decorated bishydrazone moieties bridged with the aliphatic linker (Figure 8and ESI Figures S75-S78). 


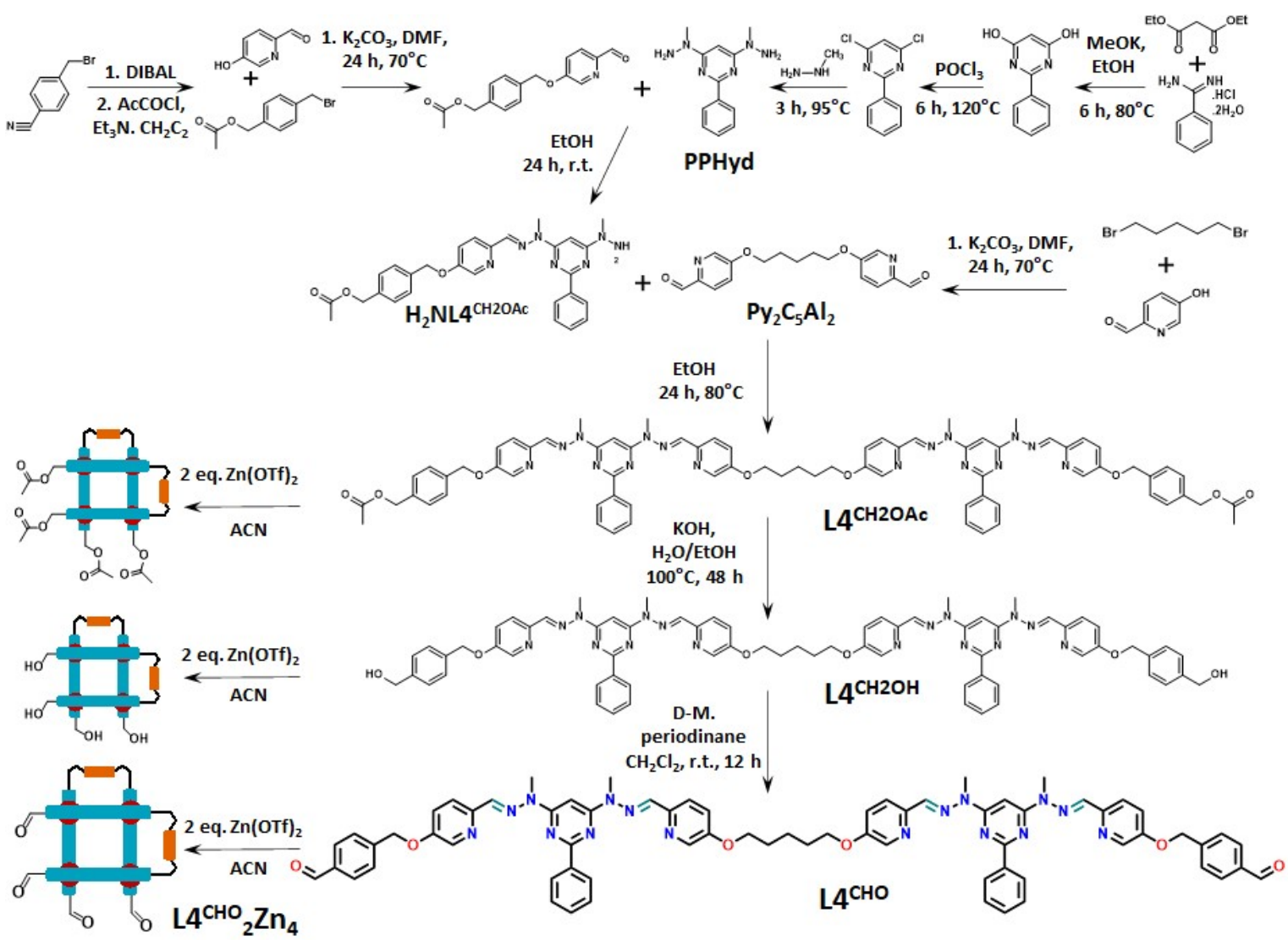

Figure 8: Synthesis of the ligands $4^{X}(X=C H 2 O A c, C H 2 O H, C H O)$ and of the corresponding functionalized folded grids/double hairpins $\mathbf{L} 4^{X}{ }_{4} \boldsymbol{Z n}_{4}$.

\section{Complexation of double-subunit ligands with metal cations}

All metal complexes described below were made by mixing the appropriate ligand $\left(\mathbf{L} 3^{\mathbf{x}_{\text {or }}}\right.$ $\mathbf{L 4}^{\mathbf{X}}$ ) and $\mathrm{Zn}(\mathrm{OTf})_{2}$ in a 1:2 ligand/Zn(II) ratio in acetonitrile and heating overnight at $70{ }^{\circ} \mathrm{C}$. The efficiency of the complex formation was strongly dependent on the exactitude of theligand to metal ratio. In case of $\mathbf{L 3}^{\mathbf{X}}$, the assembly of the complex withZn(OTf $)_{2}$ was further manifested by the development of an orange colour of the solution.

The ${ }^{1} \mathrm{H}$ NMR spectrum of the $\mathbf{L} 3^{\mathbf{C} 4} / \mathbf{Z n}$ (II) mixture in acetonitrile showedthe characteristic sets of signals for a [2x2] grid structural motivein the region between 5.5 and 6 ppm (Figure 9) belonging to phenyl substituenton the pyrimidine group intercalated between the ligands(Figure 10) [10, 15d].

Further inspection of the proton NMR spectrum showed the doublingof a most of the ${ }^{1} \mathrm{H}$ signal (Figure 9), which could be attributed totwo very different assemblies: "grid of grids" and double hairpincomplexes (depicted in Figure 9 Top).In boththe inner and outer ligands experience different chemical surroundings hence the doubling of the proton signals.Further 
analysis with the DOSY NMR and ESI-MS of several complexes with different alkyl-chain bridges suggested the presence of a specieswith $\mathbf{L 3}^{\mathbf{X}}{ }_{2} \mathbf{Z n}_{4}$ constitution (ESI Figure S79-S92 and Table S1). The longer the bridge, the cleaner wasthe observed $\mathbf{L} 3^{\mathbf{X}}{ }_{2} \mathbf{Z n}_{4}$ assembly. Finally, in the case of the $\mathbf{L 3}{ }^{\mathbf{C 5}}$ ligand, the double hairpin $\mathbf{L 3}^{\mathbf{C 5}}{ }_{2} \mathbf{Z n}_{4}$ (ESI Figure S86-88) constitution was unequivocally established byX-ray structure determination of a suitable single crystal (obtained by vapour diffusion of diisopropyl ether into an acetonitrile or nitromethane solution of the complex, R1 = $12.98 \%$ ). (Figures 10 and ESI Figure S89)
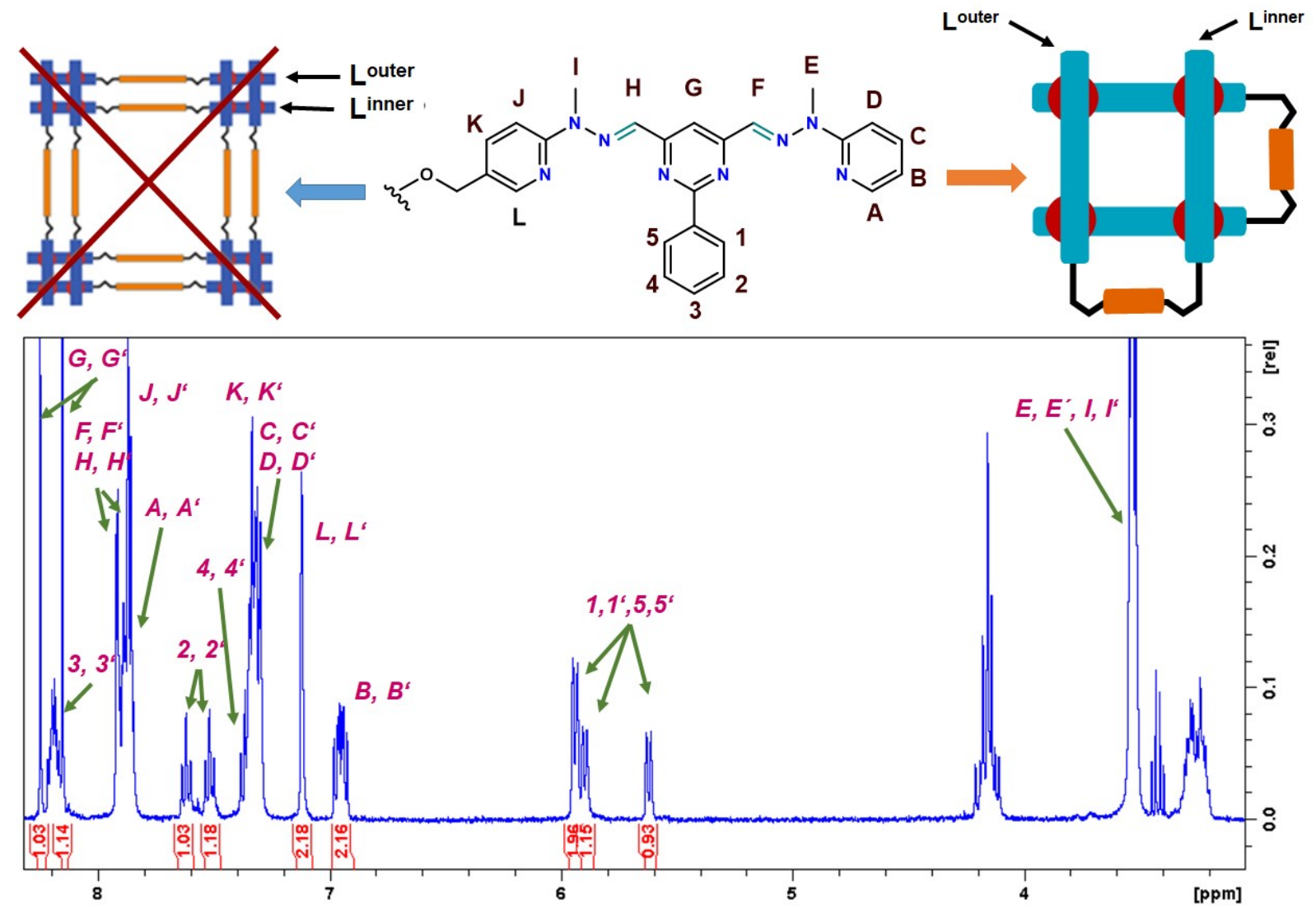

Figure 9: Top: Two possible structures, which could provide $a^{l} H$ NMR spectrum with doubling of the signals: "grid of grids" array on the left and double hairpin on the right. Bottom: Assignment of the ${ }^{1} H$ NMR signals of a solution of a recrystallized sample of ${ }_{\mathbf{L} 3}{ }^{\mathrm{CH}}{ }_{2} \mathbf{Z n}_{4}$. A grid assembly may be identified from characteristic peaks 1 and 5 . It is alsopossible to identify two sets of signals for most of theprotons.

The X-ray structure revealed a grid-type complexconsistingof twoligands bent around the O- $\mathrm{CH}_{2}$ - unitin a double-hairpins fashionof $\mathbf{L 3}^{\mathbf{X}}{ }_{2} \mathbf{Z n}_{4}$ constitution. To hinderthe observed folding, a phenyl ring was introduced in place of a flexible alkyl chains $\left(\mathbf{L 3}^{\mathbf{P h}}\right)$. Nonetheless, again astructure similar toL3 ${ }^{\mathbf{C 4}-\mathbf{C 5}}$ was obtained (see ESI Figures S79, S86, S90) with $\mathbf{L 3}{ }^{\mathrm{Ph}}$ ligand folding around connecting $-\mathrm{O}-\mathrm{CH}_{2}$ - motive into an $\mathbf{L 3}^{\mathbf{P h}}{ }_{2} \mathbf{Z n}_{4}$ complex, as 
shown by itssingle crystal X-ray structure determination. (vapourdiffusion of diisopropylether into $\mathrm{MeNO}_{2}, \mathrm{R} 1=13.21 \%$, Figure 10 and ESI Figure S93).

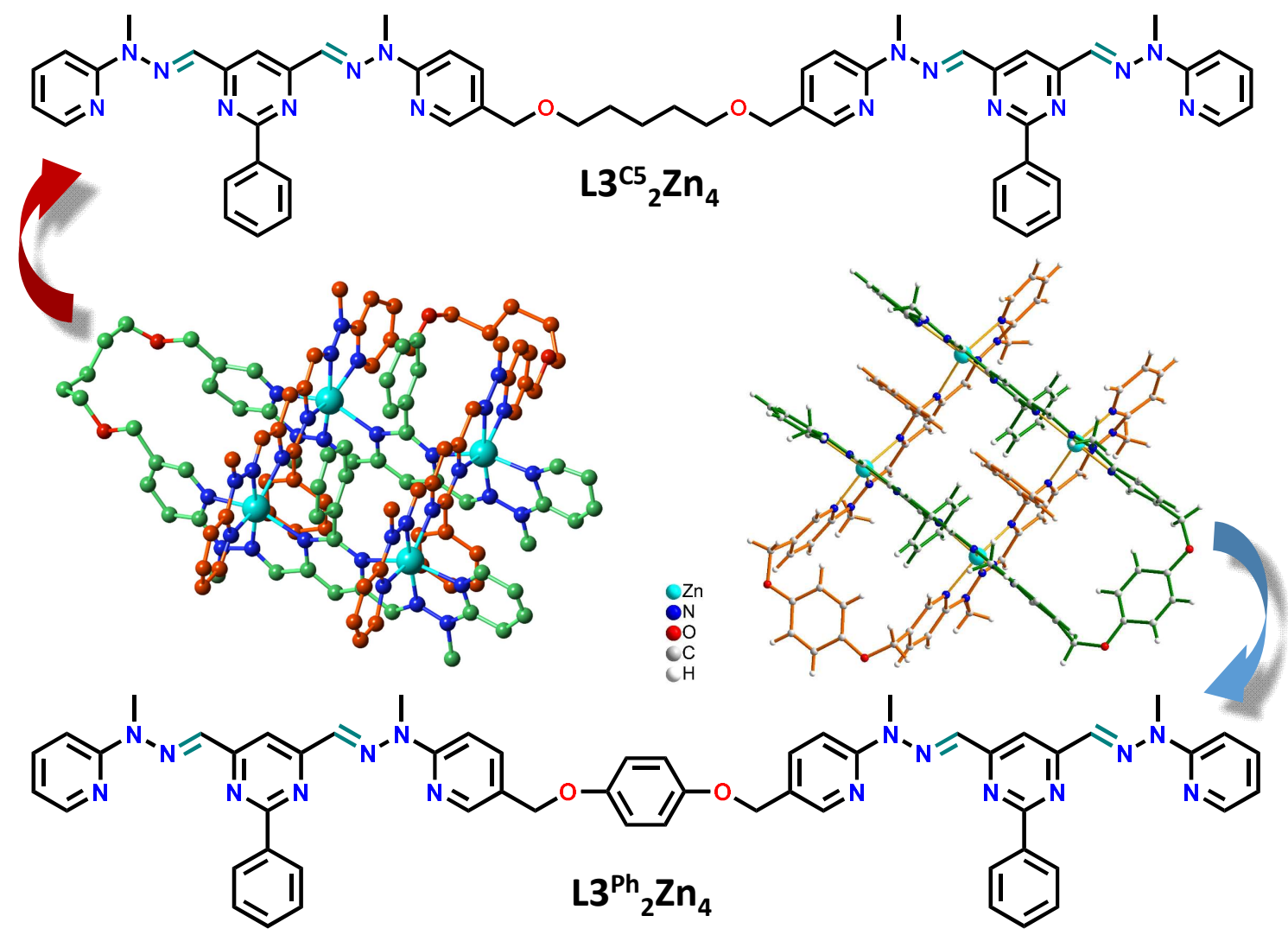

Figure 10:The folded nature of the Zn(II) grids formed from ligands $\mathbf{L 3}^{\mathrm{C5}}{ }_{2} \mathbf{Z n}_{4}$ and $\mathrm{L}^{\mathrm{Ph}}{ }_{2} \mathbf{Z} \mathbf{n}_{4}$ and their respective crystal structures.

Interestingly, the doublehairpinfolding provides a novel building block presenting an advantageous geometric arrangement of two open neighbouring sides and two sides blocked with the folded bridge. If properly functionalized, this spatial differentiationcould serve for interconnection into a geometrically regular 4x[2×2] "grid of grids" type array (Figure 9, Top left).To this end and in line with the previousperipheral decoration of grids, we focused on the on the introduction of aldehyde groups on theavailableunsubstituted open facesofthe [2x2] gridbearingtwobridgedfaces by meansof the $\mathbf{L} 4^{\mathrm{CHO}}$ ligand bearing terminal aldehyde groups as shown in Figures 6and 8.

In general, all the $\mathbf{L} 4^{\mathbf{x}}$ ligands have low solubility in common organic solvents (especially $\mathbf{L 4}^{\mathbf{C H 2 O H}}$ ), but upon the complexation with $\mathrm{Zn}(\mathrm{II})$ in acetonitrile all three cases display a clean formation of $\mathbf{L} 4^{\mathbf{X}}{ }_{2} \mathbf{Z n}_{\mathbf{4}}$ double hairpins. (Figures8 and 11, ESI Figure 104)Figure 11then illustrates this assembly forL4 ${ }^{\mathbf{C H O}}{ }_{2} \mathbf{Z n}_{\mathbf{4}}$ from its ligand $\mathbf{L 4}{ }^{\mathbf{C H O}}$ and $\mathrm{Zn}(\mathrm{OTf})_{2}$ after $12 \mathrm{~h}$ at 70 ${ }^{\circ} \mathrm{C}$ in $\mathrm{ACN} .{ }^{1} \mathrm{H}$ NMR comparison between the ligand and grid(Figure 11) showsall the characteristics of the double hairpins assembly as described for $\mathbf{L 3}^{\mathbf{C 4}}{ }_{2} \mathbf{Z n}_{\mathbf{4}}$ (Figure 9): the 
splitting of phenyl proton resonances [10][15d], as well as a doubling of all the proton signals (for the assembly of $\mathbf{L 4}{ }^{\mathbf{C H}^{2 O A c}}$ and $\mathbf{L 4}{ }^{\mathbf{C H}^{\mathbf{H O H}}}$ see ESI Figures S94, S98 and S104).

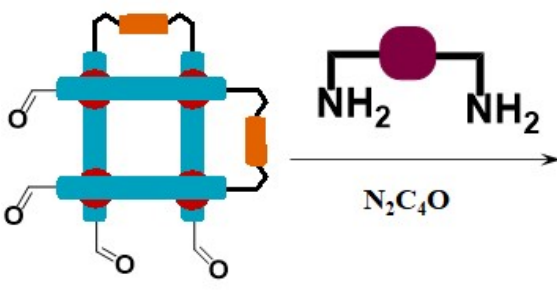

$\mathrm{L}^{\mathrm{CHO}}{ }_{4} \mathrm{Zn}_{4}$

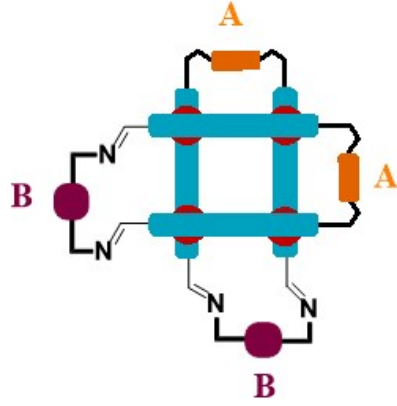

B

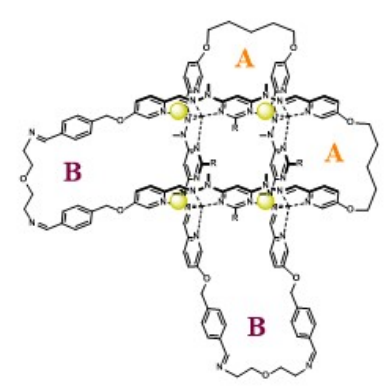

$\mathrm{L}_{4}^{\mathrm{CHN}}{ }_{4} \mathrm{Zn}_{4}\left(\mathrm{~N}_{2} \mathrm{C}_{4} \mathrm{O}\right)_{2}$

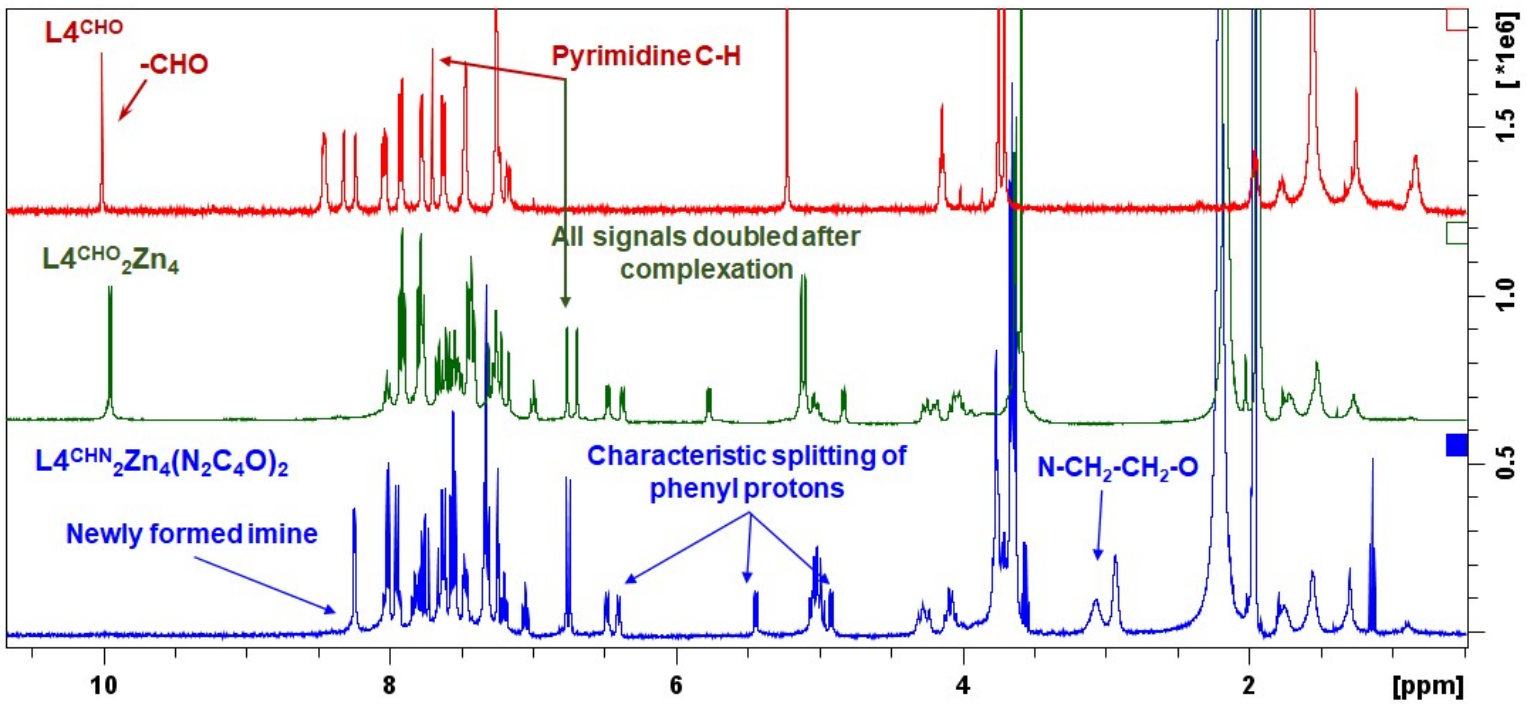

Figure 11: Top: Schematic representation of the doubly bridged complex $\boldsymbol{L}{ }^{\mathrm{CHN}}{ }_{4} \mathbf{Z n}_{4}\left(\mathbf{N}_{2} \boldsymbol{C}_{4} \mathbf{O}\right)_{2}$ presenting two different faces.Bottom:Comparison of the ${ }^{1} \mathrm{H}$ $\mathrm{NMR}$ spectra of ligand $\mathrm{L4}^{\mathrm{CHO}}\left(\mathrm{CDCl}_{3}\right)$ and of the [2x2] grid-type complexes $\mathrm{L4}^{\mathrm{CHO}}{ }_{4} \mathrm{Zn}_{4}\left(C D_{3} \mathrm{CN}\right)$ and $\mathbf{L} 4^{\mathrm{CHN}}{ }_{4} \mathrm{Zn}_{4}\left(\mathrm{~N}_{2} \mathrm{C}_{4} \mathrm{O}\right)_{2}\left(C D_{3} \mathrm{CN}\right)$.

In addition to two sides connected via an alkyl bridge, the assembled $\mathbf{L 4}{ }^{\mathrm{CHO}}{ }_{2} \mathrm{Zn}_{\mathbf{4}}$ grid also presentsfour aldehyde functions protruding out from orthogonal faces of the square structure. This makes $\mathbf{L 4}^{\mathbf{C H O}}{ }_{2} \mathbf{Z n}_{\mathbf{4}}$ a target for a DCC decoration which was further testedagain by the condensation with the previously used $\mathbf{N}_{2} \mathbf{C}_{4} \mathbf{O}$. The ${ }^{1} \mathrm{H}$ NMR spectra in Figure 11 (ESI Figure S105) show the disappearance of the aldehyde signals upon $\mathbf{N}_{2} \mathbf{C}_{4} \mathbf{O}$ addition and appearance of new imine signals at $8.5 \mathrm{ppm}$ further confirming the decoration of the peripheral aldehyde groups. Furthermore, the assignations of the main peaks in the mass spectrum indicate the formation of a single entity corresponding to the grid with twice $\mathbf{N}_{\mathbf{2}} \mathbf{C}_{\mathbf{4}} \mathbf{O}$ interconnected ligands (ESI Figure S107). The resulting $\mathbf{L 4}^{\mathbf{C H N}}{ }_{2} \mathbf{Z n}_{4}\left(\mathbf{N}_{2} \mathbf{C}_{4} \mathbf{O}\right)_{2}$ is a hybrid species between $\mathrm{L2}^{\mathrm{CHN}}{ }_{4} \mathrm{Zn}_{4}\left(\mathrm{~N}_{2} \mathrm{C}_{4} \mathrm{O}\right)_{4}$ and $\mathrm{L3}^{\mathrm{C5}}{ }_{2} \mathrm{Zn}_{4}$, having two faces bridged withtwo $\mathbf{N}_{2} \mathrm{C}_{4} \mathrm{O}$ and the same time the other two sides bent around and connected through the pentamethylene bridge. 


\section{Conclusion}

The present work describes the design of novel types of functionalized ligands and their conversion into metallosupramolecular architectures based on a [2x2] grid-type motif. It also provides information about the requirements for successful assembly of such complex ligands into [2x2] grid-type arrays. The eightfold aldehyde decorated derivatives may be usedfor variousmultivalentfunctional decorations by imine formation thus offering a framework for performing high diversity dynamic covalent chemistry. Further, double subunit ligands were developed which by condensation with appropriate diamines lead to the generation of "double hairpins"metallo-supramolecular architectures, a new family of doubly-folded [2x2] grids of $\mathbf{L}_{2} \mathbf{Z n}_{4}$ composition presenting different bridges located in orthogonal orientation.Their structure was unequivocally established by single crystal X-ray diffraction of several samples.

The ability to differentiate the faces of the [2x2]square grid motif makes such complexes appealing for generating assemblies that present specific geometrical positioning. They also represent building blocks that unlock possible extension towards the generation of 2D arrays. The eight-fold aldehydes as well as the oriented double-hairpins tetra-aldehydes offer templates for performing high diversity imine-based dynamic covalent chemistry. In addition one may note that the double hairpins are inherently chiral and thus offer further access to structurally complex architectures.

The metallosupramolecular architectures presentedopen perspectives forthe implementation of dynamic covalent self-assembly towards the multiple decoration of [2x2] square grids and the generationof 2D patterns based on "grids of grids" arrays. 


\section{Acknowledgements}

We thank Dr. Olaf Führ, Prof. Dieter Fenske, Lydia Brelot and Corinne Bailly for the crystal structure determinations. We thank the ANR (grant DYNAFUN), the ERC (Advanced Research Grant SUPRADAPT 290585), the University of Strasbourg Institute of Advanced Study (USIAS), the International Center for Frontier Research in Chemistry (icFRC) and the CNRS for financial support. J.H. thanks the University of Strasbourg for a doctoral fellowship. A.S. thanks Prof. Sebastiano Campagna and the University of Messina for the Nanosolar project fellowship and the University of Strasbourg for a post-doctoral fellowship. We also thank Karlsruhe Nano Micro Facility (KNMF) for financial support of the Karlsruhe $\mathrm{X}$-ray facility.

\section{Supporting information.}

Additional experimental details and crystallographic data can be found in related Electronic Supporting Information (ESI). CIF files and CCDC numbers for complexes: $\mathbf{L 3}^{\mathbf{P h}}{ }_{2} \mathbf{Z n}_{\mathbf{4}}$ 2087824; $\mathbf{L 3}^{\mathbf{C 5}}{ }_{2} \mathbf{Z n}_{4}-2087825 ; \mathbf{L 2}^{\mathbf{C H O}}{ }_{4} \mathbf{Z n}_{\mathbf{4}^{-}}$2087826; $\mathbf{L 2}{ }^{\mathbf{C H O}}{ }_{2} \mathbf{A g}_{2}-2087823$ are available at https://www. ccdc.cam.ac.uk/. 


\section{References}

[1] For a few recent papers, see: a) Ahmedova, A. Front. Chem., 2018, 6:620 (Biomedical Applications of Metallosupramolecular Assemblies-Structural Aspects of the Anticancer Activity); b) Sosa-Vargas, L.; Kim, E.; Attias, A.-J. Mater. Horiz., 2017,4, 570-583 (Beyond "decorative" 2D supramolecular self-assembly: strategies towards functional surfaces for nanotechnology); c) Wang, H.; Li, Y.; Li, N.;Filosa, A.; Li, X.Nat. Rev. Mater., 2021, 6, 145-167 (Increasing the size and complexity of discrete 2D metallosupramolecules.)

[2] a) Ruben, M.; Rojo, J.; Romero-Salguero, F. J.; Uppadine, L. H.; Lehn, J.-M. Angew. Chem.: Int. Ed.2004,43, 3644-3662 (Grid-Type Metal Ion Architectures: Functional Metallosupramolecular Arrays); b)Hardy, J. G. Chem. Soc. Rev.2013,42, 7881-7899 (Metallosupramolecular grid complexes: towards nanostructured materials with high-tech applications); c) Stadler, A.-M. Eur. J. Inorg. Chem2009, 4751-4770. (Grids with Unusual, High Nuclearity - A Structural Approach); d) Dawe, L. N.; Shuvaev, K. V.; Thompson, L. K. Chem. Soc. Rev.2009,38, $2334-2359$ (Polytopic liganddirected selfassembly—polymetallic [ $n \times n]$ grids versus non-grid oligomers); e) Barboiu , M.; Stadler, A.-M.; Lehn, J.-M. Angew. Chem. Int. Ed.2016,55,4130-4154 (Controlled Folding, Motional, and Constitutional Dynamic Processes of Polyheterocyclic Molecular Strands);

[3] a) Pischel,U. Angew.Chem.Int.Ed.2007,46,4026-4040 (Chemical Approaches to Molecular Logic Elements for Addition and Subtraction); b) Lent, C. S.; Tougaw, P. D. Proc. IEEE1997,85, 541 (A DeviceArchitectureforComputingwithQuantumDots); c) Pulizzi, F. Nat. Mater.2012,11, 367 (Spintronics)

[4] a) Ruben, M.; Breuning, E.; Gisselbrecht, J.-P.; Lehn, J.-M.Angew. Chem. Int. Ed.2000,39, 4139-4142 (Multilevel molecular electronic species: electrochemical reduction of a [2 $\times 2] \mathrm{Co}_{4}$ II grid-type complex by 11 electrons in 10 reversible steps); b) Zhao, L.; Xu, Z.; Grove, H.; Milway, V. A.; Dawe, L. N.; Abedin, T. S. M.; Thompson, L. K.; Kelly, T. L.; Harvey, R. G.; Miller, D. O.; Weeks, L.; Shapter, J. G.; Pope K. J. Inorg. Chem. 2004, 43, $3812-3824$ (Supramolecular Mn(II) and Mn(II)/Mn(III) GridComplexes with $\left[\mathrm{Mn}_{9}\left(\mu_{2}-\mathrm{O}\right)_{12}\right]$ Core Structures. Structural, Magnetic, and Redox Properties and Surface Studies ); c) Milway, V. A.; Abedin, T. S. M.; Niel, V.; Kelly, T. L.; Dawe, L. N.; Dey, S. K.; Thompson, D. W.; Miller, D. O.; Alam, M. S.; Müller,P.; Thompson L. K. Dalton Trans. , 2006, 2835-2851 (Supramolecular 'flat' Mng grid complexes-towards functional molecular platforms); d)Osorio, E. A.; Ruben, M.; Seldenthuis, J. S.; Lehn, J. M.; van der Zant, H. S. Small, 2010, 6, 174-178 (Conductance Switching and Vibrational Fine Structure of a $[2 \times 2] \mathrm{Co}^{I I}{ }_{4}$ Gridlike Single Molecule Measured in a Three-Terminal Device); e) Madalan, A.; Cao, X. Y.; Rogez, G.; Lehn, J.-M. Inorganic Chemistry2014,53, 4275-4277; f) Wang, Y.-T.; Li, S.-T.; Wu, S.-Q.; Cui, A.-L.; Shen, D.-Z.; Kou, H.-Z. J. Am. Chem. Soc.2013,135, 5942-5945 (Spin Transitions in Fe(II) Metallogrids Modulated by Substituents, Counteranions, and Solvents)

[5] a) Semenov, A.; Spatz, J. P.; Moller, M.; Lehn, J.-M.; Sell, B.; Schubert, D.; Weidl, C. H.; Schubert, U. S. Angew. Chem. Int. Ed.1999,38, 2547-2550 (Controlled Arrangement of Supramolecular Metal Coordination Arrays on Surfaces); b) Semenov, A.; Spatz, J. P.; Lehn, J.-M.; Weidl, C. H.; Schubert, U. S.; Moller, M. Applied Surface Science 1999,144/145, 456-460 (STM studies on monolayers of [Co(L)4]A8 metallogrids on graphite); c) Mourran, A.; Ziener, U.; Moller, M.; Breuning, E.; Ohkita, M.; Lehn, J.M. Eur. J. Inorg. Chem.2005, 2641-2647 (Two Morphologies of Stable, Highly Ordered 
Assemblies of a Long-Chain-Substituted [2 ×2]-Grid-Type FelI Complex Adsorbed on $H O P G)$

[6] a) Breuning, E.; Ziener, U.; Lehn, J.-M.; Wegelius, E.; Rissanen, K. Eur. J. Inorg. Chem 2001, 1515-1521 (Two-Level Self-Organisation of Arrays of [2×2] Grid-Type Tetranuclear Metal Complexes by Hydrogen Bonding); b) Ruben, M.; Ziener, U.; Lehn, J.M.; Ksenofontov, V.; Gutlich, P.; Vaughan, G. B. M. Chem. Eur. J.2005,11, 94-100 (Hierarchical Self-Assembly of Supramolecular Spintronic Modules into 1D-and 2D-Architectures with Emergence of Magnetic Properties); c) Stefankiewicz, A. R.; Rogez, G.; Harrowfield, J.; Sobolev, A. N.; Madalan, A.; Huuskonen, J.;Rissanen, K.; Lehn, J.-M. Dalton Trans., 2012, 41, 13848 (Self-orderingofmetallogridcomplexes via directed hydrogen-bonding)

[7] Harrowfield, J.; Lehn, J.-M. Chem. N.Z.2011, 75, 170-173 (Multifunctionality and Multivalency Generation by Self-Assembly ofGrid-type metallosupramolecularArchitectures); b) Chmielewski, Michal J.; Buhler, Eric; Candau, Jean; Lehn, Jean-Marie Chem.-Eur. J.2014, 20, 6960-6977 (MultivalencybySelf-Assembly: Binding ofConcanavalin A toMetallosupramolecularArchitecturesDecoratedwith Multiple Carbohydrate Groups); c) Tielman, P.; Marchal, A.; Lehn, J.-M. Tetrahedron Letters2005,46, 6349-6353 (Synthesis of side-chain functionalised ligands for the generation of quartet receptor arrays via self-assembly of [2×2] grid complexes). d) Stefankiewicz, A. R.; Rogez, G.; Harrowfield, J.; Drillon, M.; Lehn, J.-M. Dalton Trans.2009, 5787-5802 (Structural features directing the specificity and functionality of metallo-supramolecular grid-type architectures)

[8] Cao, X.-Y.; Harrowfield, J.; Nitschke, J.; Ramírez, J.; Stadler, A.-M.; Kyritsakas-Gruber, N.; Madalan, A.; Rissanen, K.; Russo, L.; Vaughan, G.; Lehn, J.-M. Eur. J. Inorg. Chem.2007, 2944-2965 (Generation of [2×2] Grid Metallosupramolecular Architectures from Preformed Ditopic Bis(acylhydrazone) Ligands and through Component Self-Assembly)

[9] a) Stadler, A.-M.; Burg, C.; Ramírez, J.; Lehn, J.-M. Chem. Commun.2013,49, 5733-5735 (Grid-double-helicate interconversion); b) Stadler, A.-M.; Ramirez, J.; Lehn, J.-M.; Vincent B. Chem. Sci.2016,7, 3689-3693(Supramolecularreactionsof metalloarchitectures: $\mathrm{Ag}_{2}$-double-helicate/Zn $4_{4}$ grid, $\mathrm{Pb}_{4^{-}}$grid/ $/ \mathrm{Zn}_{4^{-}}$grid interconversions, and $\mathrm{Ag}_{2^{-}}$ double-helicate fusion); c) Mittal,N.; Saha, M. L.;SchmittelM. Chem. Commun., 2016, 52, 8749-8752 (Fully reversible three-state interconversion of metallosupramolecular architectures ); d) Ayme, J.-F.; Lehn, J.-M.; Bailly, C.; Karmazin L. J. Am. Chem. Soc. 2020, 142, 12, 5819-5824 (Simultaneous Generation of a [2 $\times 2]$ Grid-Like Complex and a Linear Double Helicate: a Three-Level Self-Sorting Process)

[10] a) Rojo, J.; Romero-Salguero, F. J.; Lehn, J.-M.; Baum, G.; Fenske, D. Eur. J. Inorg. Chem. 1999, 1421-1428 (Self-Assembly, Structure, and

PhysicalPropertiesofTetranuclearZnII and CoIIComplexesof [2 $\times 2]$ Grid-Type); b)

Hanan, G. S.; Volkmer, D.; Schubert, U. S.; Lehn, J.-M.; Baum, G.; Fenske, D. Angew. Chem. Int. Ed. Engl.1997,36, 1842-1844 (Coordination Arrays: Tetranuclear Cobalt(II) Complexes with [2×2]-Grid Structure)

[11] For a selectionofreviewsspecifically on dynamiccovalentchemistry, see, for instance: a) Lehn, J.-M. Chem. - Eur. J.1999, 5,2455-2463 (Dynamic Combinatorial Chemistry and Virtual Combinatorial Libraries); b) Rowan, S. J.; Cantrill, S. J.; Cousins, G. R.; Sanders, J.K. M.; Stoddart, J. F. Angew. Chem., Int. Ed.2002, 41, 898-952 (DynamicCovalentChemistry);c) Corbett, P. T.; Leclaire, J.; Vial, L.; West, K. R.; Wietor, J.-L.;Sanders, J. K. M.; Otto, S. Chem. Rev.2006, 106, 3652-3711 
(DynamicCombinatorialChemistry);d) Ladame, S. Org.Biomol. Chem.2008, 6, 219-226 (Dynamiccombinatorialchemistry: on theroad to fulfillingthepromise); e) Miller, B. L.DynamicCombinatorialChemistry; Wiley: Chichester, 2010. f) Reek, J.N. H.; Otto, S. DynamicCombinatorialChemistry; Wiley-VCH:Weinheim, 2010. g) Hunt, R. A. R.; Otto, S. Chem. Commun.2011,47, 847-855 (Dynamiccombinatoriallibraries: newopportunities in systemschemistry); h) Belowich, M. E.; Stoddart, J. F. Chem. Soc. Rev.2012,41, 2003-2024 (Dynamic imine chemistry);

[12] a) Goral, V.; Nelen, M. I.; Eliseev, A. V.; Lehn J.-M. PNAS, 2001, 98, 1347-1352 (Double-level "orthogonal" dynamiccombinatoriallibraries on transition metal template); b) Cao X.-Y., (2009), Self-organisationofmultifunctionalmetalloarchitectures. (Doctoraldissertation), University ofStrasbourg; c) Santoro, A., Holub, J., Fik-Jaskółka, M.A., Vantomme, G., Lehn, J.-M. Chem. Eur. J., 2020, 26(67), 15664-15671 (DynamicHelicatesSelf-AssemblyfromHomo- andHeterotopicDynamicCovalent Ligand Strands);

[13]Ciesielski, A.; El Garah, M.; Haar, S.; Kovaříček, P.; Lehn, J.-M.; Samori, P. Nat. Chem., 2014, 6,1017-1023, (Dynamiccovalentchemistryofbisiminesatthe solid/liquid interface monitored by scanningtunnellingmicroscopy)

[14]Holub, J.; Santoro, A.; Lehn J.-M. Inorg. Cim. Acta, 2019, 494, 223-231

(Electronicabsorption and emissionpropertiesofbishydrazone [2 $\times 2]$ metallosupramoleculargrid-type architectures)

[15] a) Schmitt, J.-L.; Lehn, J.-M. Helv. Chim. Acta2003, 86, 3417-3426 (Self-Assembly of Non-Biological Polymeric Strands Undergoing Enforced Helical Self-Organization); b) Schmitt, J.-L.; Stadler, A.-M.; Kyrytsakas, N.; Lehn, J.-M. Helv. Chim. Acta2003,86, 1598-1624 (Helicity-Encoded Molecular Strands: Efficient Access by the Hydrazone Route and Structural Features); c) Uppadine, L. H.; Gisselbrecht, J.-P.; Lehn J.-M. Chem. Comm. 2004, 6, 718-719 (Protonicmodulationofredoxproperties in ionisable [2 $\times 2]$ gridlikemetalloarrays); d) Barboiu, M.; Ruben, M.; Blasen, G.; Kyritsakas, N.; Chacko, E.; Dutta, M.; Radekovich O., Lenton, K.; Brook, D. J. R.; Lehn, J.-M. Eur. J. Inorg. Chem.2006, 784-792 (Self-Assembly, Structure and Solution Dynamics of Tetranuclear $\mathrm{Zn}^{2+}$ Hydrazone [2×2] Grid-Type Complexes);e) Stadler, A.-M.; Kyritsakas, N.; Graff, R.; Lehn, J.-M. Chem. Eur. J.2006,12, $4503-4522$ (Formation of Rack- and Grid-Type Metallosupramolecular Architectures and Generation of Molecular Motion by Reversible Uncoiling of Helical Ligand Strands); f) Ruben, M.; Lehn, J.-M.; Vaughan, G. Chem. Comm.2003, 1338-1339 (Synthesis of ionisable [2×2] grid-type metallo-arrays and reversible protonic modulation of the optical properties of the $\left[\mathrm{CoII}_{4} L_{4}\right]^{8+}$ species);

[16] Baxter, P. ; Lehn, J.-M.; Baum, G.; Fenske, D. Chem. Eur. J,2000,6, 4510-4517 (Self-Assembly and Structure of Interconverting Multinuclear Inorganic Arrays: A [4×5]-AgI ${ }_{20}$ Grid and an AgI 10 Quadruple Helicate); b) Onions, S. T.; Frankin, A. M.; Horton, P. N.; Hursthouse, M. B.; Matthews, C. J. Chem. Comm. 2003, 2864-2865 (Selfassembly of a unique hexadecanuclear $[4 \times(2 \times 2)]-P b_{16}$ 'grid of grids' type structure $)$ 